\title{
Intensive Care Management of Multiorgan Dysfunction and Hypoxic Brain Injury Secondary to Refractory Status Epilepticus
}

Sanum Kashif

ABSTRACT

Refractory Status Epilepticus (RSE) is a medical emergency that may lead to permanent brain damage or death. Mortality rate is $16-39 \%$. It is the life threatening condition in which continuous fits occur, despite treatment with benzodiazepines and one antiepileptic drug.

A 25-year-old female, brought in emergency department with high-grade fever and frequent fits. Glasgow Coma Scale (GCS) was 3/15 with unstable hemodynamics. Resuscitation started immediately and managed as status epilepticus. Patient was in multi organ failure on arrival. On the basis of history and examination, hypoxic brain injury was diagnosed initially. Later on, refractory status epilepticus (RSE) with multi organ dysfunction syndrome (MODS) was diagnosed, after necessary investigations and treatment. Patient was managed as a team with multidisciplinary approach and after continuous effort of 2 weeks, patient was successfully discharged to home.

Key Words: Intensive Care, Mutiorgan Dysfunction Syndrome (MODS), Refractory Status Epilepticus (RSE).

How to cite this: Kashif S. Intensive Care Management of Multiorgan dysfunction and Hypoxic brain injury secondary to refractory status epilepticus. Life and Science. 2021; 2(4): 199-201. doi: http://doi.org/10.37185/LnS.1.1.122

This is an Open Access article distributed under the terms of the Creative Commons Attribution License (http://creativecommons.org/licenses/by/4.0), which permits unrestricted use, distribution, and reproduction in any medium, provided the original work is properly cited.

\section{Introduction}

Refractory status epilepticus (RSE) is a neurological emergency with significant morbidity and mortality. It results from failure of the mechanism, responsible for seizure termination or from initiation mechanism that lead to abnormally prolonged seizures. The morbidity and mortality due to status epilepticus(SE), depends on the duration of epileptic activity, rapid identification of the cause of SE, comorbidities and age. SE becomes refractory (RSE) if first- and second-line treatments with antiepileptic drugs (AEDs) fail to terminate the seizure. ${ }^{1,2}$

As far as refractory status epilepticus is concerned, several EEG patterns are associated with poor prognosis, according to previous literature. Increasing evidence has emerged that patients may have a favorable outcome, even with status

Department of Anesthesia

Frontier Crops Hospital, Quetta

Correspondence:

Dr. Sanum Kashif

Assistant Professor, Anesthesia

Frontier Crops Hospital, Quetta

E-mail: sanumdr@gmail.com

Funding Source: NIL; Conflict of Interest: NIL

Received: May 21, 2020; Revised: May 21, 2021

Accepted: Sep 3, 2021

199 myoclonus and malignant EEG patterns, if aggressive management is pursued. ${ }^{3}$ Post seizures, changes in cerebral blood flow (CBF), have also been demonstrated in human temporal lobe epilepsy. According to previous single photon emission computerized tomography (SPECT) studies, temporal lobe seizures are associated with global temporal hyper perfusion during seizures, which switches to relative lateral temporal hypoperfusion immediately following seizures of less than 2 minutes and global temporal hypoperfusion after 3-15 minutes following seizures. ${ }^{4,5}$

Intensive care management of refractory status epilepticus (RSE) with multi organ dysfunction syndrome (MODS) is challenging. Patients in refractory status epilepticus (RSE) may require treatment with continuous intravenous anesthetic drugs (cIVADs) for seizure control, however, prolong use of cIVADs is associated with poor prognosis in status epilepticus (SE). ${ }^{6,7}$ Current management guidelines for refractory status epilepticus (RSE) recommend the use of intravenous continuous anesthetic therapy, such as thiopental or midazolam. ${ }^{8,9}$

\section{Case Presentation}

A 25-year-old female, brought in emergency 
department with high-grade fever and intermittent fits for 20 and 15 days respectively. Initially was taken to local clinic, but symptoms not controlled, so brought to emergency department of our hospital. On examination, her vitals showed heart rate of $131 / \mathrm{min}$, blood pressure of $80 / 35 \mathrm{mmHg}$, oxygen saturation $80 \%$ on 10 liters of $\mathrm{O} 2$, Glasgow Coma Scale (GCS) was $3 / 15$ with pin-point pupils bilaterally and bilateral coarse crackles, found on chest auscultation, so immediately resuscitated and after securing definitive airway, shifted to ICU for ventilatory support (controlled mode ventilation), with sedation and relaxation.

She remained on midazolam infusion at $2 \mathrm{mg} /$ hour due to frequent episodes of fits. Antiepileptics (Intravenous inj. Levetiracetam 500mg 8hourly, Topiramate $100 \mathrm{mg} 12 \mathrm{hourly}$ ) and broad-spectrum antibiotics (Intravenous inj. Meropenem 1 gram 8hourly) also continued. Severe hypokalemia and hypernatremia were treated accordingly (Table 1).

\begin{tabular}{ll}
\hline \multicolumn{2}{l}{ Table 1: laboratory investigations on admission } \\
\hline $\mathrm{Hb}$ & $11.0 \mathrm{gm} / \mathrm{dl}$ \\
$\mathrm{TLC}$ & $10.0 \times 10^{3} / \mathrm{ul}$ \\
$\mathrm{PLT}$ & $201 \times 10^{3} / \mathrm{ul}$ \\
$\mathrm{Urea}$ & $45 \mathrm{mmol} / \mathrm{l}$ \\
Creatinine & $422 \mathrm{umol} / \mathrm{l}$ \\
$\mathrm{Na}$ & $160 \mathrm{meq} / \mathrm{l}$ \\
$\mathrm{K}$ & $2.9 \mathrm{meq} / \mathrm{l}$ \\
$\mathrm{CT}-\mathrm{Brain}$ & $\mathrm{HYPOXIC} \mathrm{INJURY}$ \\
$\mathrm{CSF}$ & $\mathrm{NORMAL}$ \\
$\mathrm{ABGs}$ & $\mathrm{PH}: 7.08$, \\
& $\mathrm{PCO} 2: 23.9 \mathrm{mmHg}, \mathrm{PO} 2: 55 \mathrm{mmHg}$, \\
& $\mathrm{HCO}: 7.1, \mathrm{SO} 2: 90.1 \%$ \\
\hline
\end{tabular}

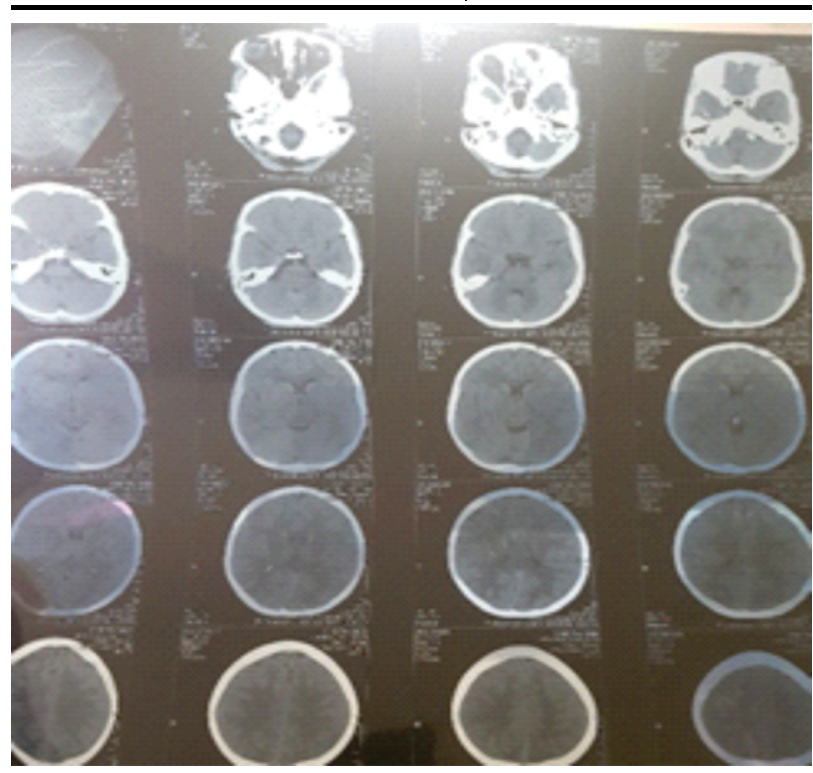

Fig 1: CT-Brain
Acute Kidney Injury (likely secondary to rhabdomyolysis or sepsis) diagnosed due to low urine output and high serum creatinine (Table 1) on arrival and managed accordingly with intravenous fluids and diuretics, dialysis catheter was passed for probable hemodialysis. On improvement of seizures and GCS, correction of electrolytes imbalance (Table 2 ) and hemodynamics, extubation trial was given after 4 days of mechanical ventilation.

\begin{tabular}{ll}
\hline Table 2: Laboratory investigations on extubation \\
\hline Urea & $10 \mathrm{mmol} / \mathrm{I}$ \\
Creatinine & $98 \mathrm{umol} / \mathrm{l}$ \\
$\mathrm{Na}$ & $145 \mathrm{meq} / \mathrm{l}$ \\
$\mathrm{K}$ & $4.1 \mathrm{meq} / \mathrm{l}$ \\
$\mathrm{ABGs}$ & $\mathrm{PH}: 7.28$, \\
& $\mathrm{PCO} 2: 35 \mathrm{mmHg}, \mathrm{PO} 2: 80 \mathrm{mmHg}$, \\
& $\mathrm{HCO}: 18, \mathrm{SO} 2: 92 \%$ \\
\hline
\end{tabular}

But 2 hours post extubation, patient's GCS suddenly dropped to 5 from 14 and showed arrthymias on ECG monitoring, so again mechanical ventilatory support started.

On 7th day of mechanical ventilation, tracheostomy planned due to low GCS. On $1^{\text {st }}$ post-operative day of tracheostomy, wean off trial was planned but she didn't tolerate so again shifted to synchronized intermittent mandatory ventilation (SIMV) mode for 2 more days. MRI-Brain planned due to fluctuating GCS and weaning failure but family refused due to unaffordability. Hemodynamic monitoring and ICU care continued.

On $4^{\text {th }}$ day of tracheostomy patient GCS improved to $13 / 15$ and hemodynamically stable so weaned off successfully.

On $6^{\text {th }}$ day of tracheostomy, GCS improved to $15 / 15$ so removal of tracheostomy tube done and successfully discharged to home on $7^{\text {th }}$ postoperative and $14^{\text {th }}$ day of admission.

\section{Discussion}

Refractory status epilepticus (RSE) is one of the serious neurologic emergencies, with high morbidity and mortality. Refractory status epilepticus (RSE) with multiorgan dysfunction syndrome (MODS) has poor prognosis than treatment-responsive status epilepticus (SE) and is mainly related to its etiology. ${ }^{10}$ According to different studies, RSE is the persistent SE after failure of a first-line (intravenous benzodiazepines) and one second-line antiepileptic drug (AED) (mostly valproic acid, phenytoin, levetiracetam or phenobarbital), whereas others 
suggest RSE, as status epilepticus (SE) with a duration of more than 60 minutes. ${ }^{11}$

In early $\mathrm{SE}$, increase in cerebral blood flow (CBF), protects the brain but CBF falls in late refractory SE due to sudden hemodynamical changes. Increases in cerebral metabolic rate (CMR) for glucose and oxygen also occurs throughout refractory SE. Depletion of adenosine triphosphate (ATP) and accumulation of lactate are associated with neuronal necrosis due to hypermetabolism. ${ }^{12}$ If left untreated, SE can lead to profound long-term effects through excitotoxic neuronal injury or death and alternation of neuronal networks. ${ }^{13}$ Accordingly, shorter times to treatment are associated with better outcomes. Initial management includes, administration of benzodiazepine and immediate intensive care. ${ }^{14}$ If the initial management with intravenous benzodiazepine and subsequently with antiepileptic drugs (AEDs) such as phenytoin, valproate, levetiracetam or lacosamide, fails to control seizures, patient will be labelled as having refractory SE (RSE), which will be treated with third-line anesthetic agents, such as propofol, barbiturates or midazolam. This line of treatment usually stops the seizure activity, but in some cases, seizures recur or persist upon withdrawal of third-line anesthetics. These super-refractory SE (SRSE) patients are defined as SE that persists for 24 hours or more despite treatment with third-line anesthetic agents, or persists after weaning of the third-line anesthetic agents. ${ }^{15,16}$

\section{Conclusion}

This case was unique due to the fact that Refractory Status Epilepticus (RSE) and Multiorgan Dysfunction syndrome (MODS) has very high morbidity and mortality but only due to collective effort of a multidisciplinary team in intensive care, patient was saved and successfully discharged with full GCS.

\section{Acknowledgment}

We are thankful to the family, as they gave permission for sharing this case as a Case Report to others.

\section{REFERENCES}

1. Kantanen AM, Kälviäinen R, Parviainen I, Ala-Peijari $M$, Bäcklund T, Koskenkari J, et al. Predictors of hospital and one-year mortality in intensive care patients with refractory status epilepticus: a population-based study. Critical Care. 2017; $21: 71$

2. Harris C, Gilmore E. Seizures and Status Epilepticus. In Neurocritical Care for the Advanced Practice Clinician. Springer, Cham. 2018; pp: 201-21.

3. Reynolds AS, Claassen J. Treatment of seizures and postanoxic status epilepticus. In Seminars in neurology. Thieme Medical Publishers. 2017; 37: 033-9

4. Gaxiola-Valdez I, Singh S, Perera T, Sandy S, Li E, Federico P. Seizure onset zone localization using postictal hypoperfusion detected by arterial spin labelling MRI. Brain. 2017; 140: 2895-911.

5. Bauer G, Unterberger I. Anoxic Myoclonic Status Epilepticus. InStatus Epilepticus. Springer, Cham. 2018; pp: 155-65.

6. Madžar D, Reindl C, Giede-Jeppe A, Bobinger T, Sprügel MI, Knappe RU, et al. Impact of timing of continuous intravenous anesthetic drug treatment on outcome in refractory status epilepticus. Critical Care. 2018; 22: 317.

7. Schmutzhard E, Pfausler B. Complications of the management of status epilepticus in the intensive care unit. Epilepsia. 2011; 52:39-41.

8. Bellante F, Legros B, Depondt C, Créteur J, Taccone FS, Gaspard N. Midazolam and thiopental for the treatment of refractory status epilepticus: a retrospective comparison of efficacy and safety. Journal of neurology. 2016; 263: 799806.

9. Delaj L, Novy J, Ryvlin P, Marchi NA, Rossetti AO. Refractory and super-refractory status epilepticus in adults: a 9-year cohort study. Acta Neurologica Scandinavica. 2017; 135: 929.

10. Reznik ME, Berger K, Claassen J. Comparison of intravenous anesthetic agents for the treatment of refractory status epilepticus. Journal of clinical medicine. 2016; 5:54.

11. Lehtimäki $\mathrm{K}$, Långsjö JW, Ollikainen J, Heinonen $\mathrm{H}$, Möttönen T, Tähtinen $T$, et al. Successful management of super-refractory status epilepticus with thalamic deep brain stimulation. Annals of neurology. 2017; 81: 142-6.

12. Beretta S, Coppo A, Bianchi E, Zanchi C, Carone D, Stabile A, et al. Neurologic outcome of postanoxic refractory status epilepticus after aggressive treatment. Neurology. 2018; 91: e2153-62.

13. Hocker S. Treatment of Refractory and Super-Refractory Status Epilepticus. InStatus Epilepticus. Springer, Cham. 2018; pp: 201-14.

14. Strzelczyk A, Ansorge S, Hapfelmeier J, Bonthapally V, Erder $\mathrm{MH}$, Rosenow F. Costs, length of stay, and mortality of super-refractory status epilepticus: a population-based study from Germany. Epilepsia. 2017; 58: 1533-41.

15. Rossetti AO, Hirsch LJ, Drislane FW. Nonconvulsive seizures and nonconvulsive status epilepticus in the neuro ICU should or should not be treated aggressively: A debate. Clinical Neurophysiology Practice. 2019; 4: 170-7.

16. Holtkamp M. Pharmacotherapy for refractory and superrefractory status epilepticus in adults. Drugs. 2018; 78: 30726. 